\title{
A LIBERDADE DE EXPRESSÃO E O DIREITO DE REUNIÃO NA SOCIEDADE PLURAL
}

\author{
WELLINGTON MAGALHÃES
}




\title{
A LIBERDADE DE EXPRESSÃO E O DIREITO DE REUNIÃO NA SOCIEDADE PLURAL
}

Recebimento: $24 / 01 / 2013$

Aceite: $28 / 102013$

Wellington Magalhães ${ }^{1}$

\section{RESUMO}

O objetivo central deste trabalho é o de analisar a liberdade de expressão e o direito de reunião sob a perspectiva do confronto ideológico da modernidade. Também se pretende investigar o papel do poder público diante desse confronto de ideologias, ou seja, em que medida a intervenção estatal se mostra legítima no que tange ao exercício e efetividade desses direitos fundamentais.

Palavras-Chave: Direitos fundamentais. Liberdade de expressão e de reunião. Confronto ideológico. Sociedade plural.

\begin{abstract}
The objective of this work is to analyze the freedom of expression and the right to reunão the perspective of ideological confrontation of modernity. Intends to investigate the action of the government and the clash of ideologies. In which the extent to which state intervention is legitimate in defending these rights.
\end{abstract}

Keywords: Fundamental rights. Freedom of expression and assembly. Ideological confrontation. Plural society.

\footnotetext{
1 Wellington Magalhães é juiz de Direito do Tribunal de Justiça do Estado do Tocantins. Atualmente cursa mestrado em Direito Constitucional pela Universidade de Coimbra (Portugal). Possui título de especialista em Direito Tributário pela Universidade do Sul de Santa Catarina (UNISUL) e em Direitos Humanos pelo Ius Gentium Conimbrigae - Centro de Direitos Humanos da Faculdade de Direito da Universidade de Coimbra. Foi advogado militante em Brasília/DF, professor do núcleo de prática jurídica do Centro Universitário de Brasília (UniCEUB) e Procurador do Município de Manaus-AM.
} 


\section{INTRODUÇÃO}

O presente trabalho é fruto de investigação científica acerca do direito de liberdade de expressão e do direito de reunião. O problema de partida circunscreve-se ao papel do Estado diante das disputas ideológicas que moldam a história da humanidade, ora garantindo a convivência pacífica das variadas visões de mundo, ora rejeitando comportamentos inadequados à realidade plural na qual se vive. $\mathrm{O}$ cerne da questão é o de tentar descobrir quais são as linhas de atuação do Estado nessa missão de salvaguardar os direitos, as liberdades e as garantias fundamentais de uma sociedade que se mostra cada vez mais plural e fragmentada. $\mathrm{O}$ trabalho está dividido em dois capítulos principais. No primeiro, tratar-se-á da liberdade de expressão e sua raiz histórica, sua evolução no tempo e o atual estágio em que se encontra. Já num segundo momento, será tratado o direito de reunião como instrumento de exercício das liberdades fundamentais, nomeadamente da liberdade de expressão, ocasião em que também se apresentará breve estudo de caso. O último capítulo é totalmente dedicado às mais relevantes conclusões a que se chega, todavia, sem se descartarem aquelas lançadas ao longo de todo o trabalho. 


\section{A LIBERDADE DE EXPRESSÃO}

\subsection{A liberdade de expressão a partir da liberdade religiosa: a nova ordem secular}

A história da luta pelo direito de expressar livremente o pensamento, ideias e opiniões está intimamente ligada ao confronto teológico-político que marcou o fim da Idade Média, movimento este que culminaria com a queda do domínio religioso da Igreja Católica e proliferação de confissões religiosas mundo afora ${ }^{2}$. A afirmação histórica da liberdade de expressão, associada ao movimento de secularização da sociedade 3 , também serviria ao constitucionalismo liberal, designadamente aos arranjos históricos da independência dos Estados Unidos e dos ideais Iluministas da Revolução Francesa ${ }^{4}$. É nesse contexto que a liberdade de expressão assume importante papel na estruturação dos regimes democráticos e consolidação do Estado Constitucional 5 .

2 MACHADO, Jónatas E. M. A liberdade de expressão. Entre o naturalismo e a religião. Boletim da Faculdade de Direito da Universidade de Coimbra (BFD), n. 84, Coimbra, Outubro 2008: 89-187; p. 91; MACHADO, Jónatas E. M. Liberdade de expressão, interesse público e figuras públicas e equiparadas. Boletim da Faculdade de Direito da Universidade de Coimbra (BFD), n. 85, Coimbra, 2009: 73-109, p. 76; e MACHADO, Jónatas E. M. Liberdade de Expressão: dimensões constitucionais da esfera pública no sistema social. Stvdia Ivridica, $\mathrm{n}$. 65. Coimbra: Coimbra, 2002, p. 13.

3 BERGER, Peter. The Desecularization of the Word: Resurgent Religion and Word Politics (ed. Peter Berger). Grand Rapids: Michigan, 1999, p. 2. Disponível em: http://storage.cloversites.com/pathwaysformutualrespect/documents/Berger-Desecularization_World.pdf. Acesso em 20 de Março de 2012.

4 SILVA, Suzana Tavares da. Direitos fundamentais na arena global. Coimbra: Universidade de Coimbra, 2011, p. 18.

5 CANOTILHO, José Joaquim Gomes. Direito Constitucional e Teoria da Constituição. $7^{\text {a }}$ edição. Coimbra: Almedina, 2003, p. 92-93. Também neste sentido: TORRE, Ignacio Berdugo Gómez de La. La colucion del conflicto entre libertad de expression y honor en el derecho penal espanhol. Boletim da Faculdade de Direito da Universidade de Coimbra (BDF), 
Para Jónatas Machado, a liberdade de expressão tem sua origem no advento da idade moderna ${ }^{6}$, especialmente na pessoa do estadista inglês John Milton, considerado o pai da liberdade de expressão ${ }^{7}$. Em prefácio à tradução para o português do ensaio Areopagitica, escrito por Milton em 1644, Machado esclarece que o referido autor "advogou e praticou uma ampla liberdade de expressão religiosa", nomeadamente porque a verdade só seria realmente possível por um "processo conversacional aberto", em que todos pudessem livremente apresentar e sustentar as suas razões ${ }^{8}$.

Mas foi no confronto teológico-político, inaugurado com a Reforma Protestante, que a liberdade de expressão tomou corpo, especialmente com a queda da unidade religiosa da Igreja Católica ${ }^{9}$. A pluralidade de confissões religiosas, aliada ao processo de secularização ${ }^{10}$ da sociedade, abriu caminho à liberdade de consciência individual e, consequentemente, da autonomia da vontade pessoal ${ }^{11}$. Nessa fase da história, a cons-

vol. LXV, Coimbra, 1989: 263-275; TORRE, Ignacio Berdugo Gómez de La. Los límites entre la libertad de expressión y los derechos de la personalidad. Especial referencia a su problemática jurídico-penal. Doctrina Penal. Teoría y Prática en las Ciencias Penales, n. 53/54, Buenos Aires, 1991: 3-27; e CASTILHO, Antonio López. Acerca de la liberad religiosa en el tiempo. Revista de Estudios Políticos, $n^{\circ}$ 102, 1998: 217-230 maxime 217-219.

6 MACHADO, Jónatas E. M. Liberdade de expressão: Dimensões..., 2002, p. 18.

7 MACHADO, Jónatas E. M. A liberdade de expressão. Entre o naturalismo..., 2008, p.129; e MACHADO, Jónatas E. M. Liberdade de expressão. Dimensões..., 2002, p. 60.

8 MILTON, John. Aeropagitica. Discurso sobre a liberdade de expressão. Coimbra: Almedina, 2009, p. 8 ss.

9 MACHADO, Jónatas E. M. Liberdade religiosa numa comunidade constitucional inclusivista. Dos direitos da verdade aos direitos dos cidadãos. Coimbra: Coimbra, 1996, p. 53.

10 ADRAGÃo, Paulo Pulido. Crucifixos e minaretes: a religião no espaço público. A garantia da liberdade religiosa e a prevenção de conflitos. In: Revista da Faculdade de Direito da Universidade do Porto. Edição especial. Porto, 2010, p. 464-473, p. 468.

11 MACHADO, Jónatas E. M. Liberdade de Expressão: dimensões..., 2002, p. 18; e CAILLÉ, Alain. LAZZAREI, Chistian. SENELLART, Michel. História crítica da filosofia mo- 
ciência do indivíduo manifesta sua plena vivacidade crítica e emancipatória. A opção por uma religião passa a ser uma questão rivada, e não mais imposição da religião ou da política ${ }^{12}$.

De outro modo, também o florescimento e o progresso científico $^{13}$, em especial do racionalismo cartesiano ${ }^{14}$, contribuíram para a afirmação da liberdade de expressão, nomeadamente pelo impacto que causaria na ordem teológicopolítica até então vigente. A filosofia de René Descartes ${ }^{15}$ rejeitava toda autoridade no processo de conhecimento que não fosse a razão. Ele entendia que só se deve aceitar aquilo que se pode "compreender claramente" e "demonstrar racionalmente", ou seja, devem ser excluídos do processo de conhecimentos os dogmas religiosos, os preconceitos sociais e as censuras políticas. O conhecimento emana da Razão e somente ela pode julgar a si mesma ${ }^{16}$.

No campo da política, novas abordagens propugnavam a liberdade religiosa, podendo-se nesse particular destacar o liberalismo político de John Locke ${ }^{17}$, para quem a sociedade de homens era constituída apenas para a preservação e melhoria

ral e política. Lisboa: Verbo, 2001, p. 213.

12 MACHADO, Jónatas E. M. A liberdade de expressão. Entre o naturalismo..., 2008, p. 95; e JUSTO, A. Santos. Nótulas de história do pensamento jurídico. Coimbra: Coimbra, 2005 , p. 41 e ss.

13 MACHADO, Jónatas E. M. Liberdade de expressão: dimensões..., 2002, p. 27.

14 MACHADO, Jónatas E. M. Liberdade de expressão. Dimensões..., 2002, p. 59; e KAMBOUCHNER, Denis. Decartes (1596-1650). Felicidade e Utilidade. In: CAILLÉ, Alain. LAZZAREI, Chistian. SENELLART, Michel. História crítica..., 2001, p. 319 e ss.

15 JAPIASSÚ, Hilton. O racionalismo cartesiano. In: Curso de Filosofia. Org. REZENDE, Antônio, $13^{\mathrm{a}}$ ed. Rio de Janeiro: Jorge Zahar Editor, 2005, p. 111; e KAMBOUCHNER, Denis. Decartes.., 2001, p. 322.

16 JAPIASSÚ, Hilton. O racionalismo..., 2005, p. 111.

17 JUSTO, A. Santos. Nótulas de histórica..., 2005, p. 46. 
dos bens civis de seus membros, não competindo ao Estado

tomar partido nas questões religiosas ${ }^{18}$. Locke defendia que a religião não pertencia ao âmbito do conhecimento racional, mas sim ao da fé individual, razão pela qual não poderia haver imposição de uma crença em detrimento de outra ${ }^{19}$. Assim, mais uma vez abriram-se as portas para a elevação da razão ante as questões da fé, consolidação da autonomia individual e afirmação da liberdade de manifestação do pensamento ${ }^{20}$. Ainda sobre a obra de Locke, cumpre salientar que sua teoria seria introduzida mais tarde por Thomas Jefferson e James Madison no constitucionalismo norte-americano ${ }^{21}$.

Nessa linha de raciocínio, impende destacar a importância que a liberdade religiosa teve na Revolução Francesa. Para Jónatas Machado, "assistiu-se um outro tipo de secularização",

18 LOCKE, John. Carta acerca da tolerância. Disponível em: http://www.dhnet.org.br/ direitos/anthist/marcos/edh_locke_carta_tolerancia.pdf. Acesso em 20 de Março de 2012.

19 GUERREIRO, Sara. As fronteiras da tolerância. Coimbra: Almedina, 2005, p. 48.

20 MACHADO, Jónatas E. M. Liberdade de expressão. Dimensões..., 2002, p. 61.

21 MACHADO, Jónatas E. M. A liberdade de expressão. Entre o naturalismo..., 2008, p. 95; e MACHADO, Jónatas E. M. Liberdade de expressão. Dimensões..., 2002, p. 60. Conferir também: Art. $16^{\circ}$ da Declaração do bom povo de Virgínia, de 16 de junho de 1976: "Que a religião ou os deveres que temos para com o nosso Criador, e a maneira de cumpri-los, somente podem reger-se pela razão e pela convicção, não pela força ou pela violência; conseqüentemente, todos os homens têm igual direito ao livre exercício da religião, de acordo com o que dita sua consciência, e que é dever recíproco de todos praticar a paciência, o amor e a caridade cristã para com o próximo". Declaração de Direitos do Bom Povo de Virgínia, de 16 de junho de 1776. In: http://www.rolim.com.br/2002/_pdfs/0611.pdf. Acesso em 18 de Março de 2012. Conferir também a Primeira emenda à Constituição Americana, de 1791 que prescreve: "O Congresso não poderá fazer nenhuma lei concernente ao estabelecimento de uma religião ou proibindo o seu livre exercício, restringindo a liberdade de palavra e da imprensa, ou o direito dos cidadãos de reunir-se pacificamente e de dirigir petições ao Governo para a reparação dos seus agravos". Fonte: AMERICA, Constituição dos Estados Unidos da. Disponível em: http://www.direitobrasil.adv.br/arquivospdf/constituicoes/CUSAT.pdf. Acesso em 18 de Março de 2012. 
cuja pretensão era cortar definitivamente as ligações entre o Estado e a religião ${ }^{22}$, o que a propósito conclui-se da leitura do art. 10 da Declaração Universal dos Direitos do Homem e do Cidadão ${ }^{23}$. Segundo Sara Guerreiro, a liberdade religiosa no processo de independência americano tem uma visão mais positiva da religião, especialmente por sua contribuição nas transformações sociais ocorridas. No caso francês, todavia, a religião era mais uma das instituições vistas como "não benignas", nomeadamente pela forte perseguição religiosa que dominou os acontecimentos posteriores aos da revolução ${ }^{24}$.

Nos anos que se seguiram à independência americana e à revolução francesa, o processo de secularização da sociedade acentuou-se graças ao triunfo das "explicações naturalistas e materialistas" do Universo e da sociedade ${ }^{25}$. Ou seja, o racionalismo cartesiano e o liberalismo lockeano unem-se na busca do progresso científico, político e tecnológico. Portanto, nesse contexto de intenso confronto teológico-político em que a liberdade de expressão, inicialmente associada à liberdade religiosa, afirma-se como direito fundamental do ser humano ${ }^{26}$.

22 MACHADO, Jónatas E. M. A liberdade de expressão. Entre o naturalismo.., 2008, p. 95.

23 Art. $10^{\circ}$ Ninguém pode ser inquietado pelas suas opiniões, incluindo opiniões religiosas, contando que a manifestação delas não perturbe a ordem pública estabelecida pela Lei. DUDHC, de 1789. Disponível em: http://pfdc.pgr.mpf.gov.br/atuacao-e-conteudos-de-apoio/ legislacao/direitos-humanos/declar_dir_homem_cidadao.pdf. Acesso em 18 de Março de 2012. 24 GUERREIRO, Sara. As Fronteiras..., 2005, p. 51-52.

25 MACHADO, Jónatas E. M. A liberdade de expressão. Entre o naturalismo..., 2008, p. 96.

26 Art. $1^{\circ}$ da Primeira emenda à Constituição dos Estados Unidos da América: “O Congresso não poderá fazer nenhuma lei concernente ao estabelecimento de uma religião ou proibindo o seu livre exercício, restringindo a liberdade de palavra e da imprensa, ou o direito dos cidadãos de reunir-se pacificamente e de dirigir petições ao Governo para a reparação dos seus agravos". Constituição dos Estados Unidos da América..., acesso em 18 de Março de 2012. Conferir também o Art. $11^{\circ}$ da Declaração Universal dos Direitos do Homem e do Cidadão: “A 


\title{
Direito de opinar, manifestar, criticar e reconstruir a realidade individual e social ${ }^{27}$.
}

\author{
Hoje a liberdade de expressão encontra-se amplamente \\ consagrada no direito internacional ${ }^{28}$ e nas constituições \\ democráticas ${ }^{29}$. Como afirma Jónatas Machado, quando
}

livre comunicação dos pensamentos e das opiniões é um dos mais preciosos direitos do Homem; todo o cidadão pode, portanto, falar, escrever, imprimir livremente, respondendo, todavia, pelos abusos desta liberdade nos termos previstos na Lei”. Declaração Universal dos Direitos do Homem..., acesso em 18 de Março de 2012.

27 MACHADO, Jónatas E. M. Liberdade de expressão: Dimensões..., 2002, p. 47.

28 Art. 19. ${ }^{\circ}$ Todo o indivíduo tem direito à liberdade de opinião e de expressão, o que implica o direito de não ser inquietado pelas suas opiniões e o de procurar, receber e difundir, sem consideração de fronteiras, informações e ideias por qualquer meio de expressão. Fonte: DUDH, de 1948. Disponível em: http://www.oas.org/dil/port/1948\%20Declara\%C3\%A7\%C3\%A3o\%20 Universal\%20dos\%20Direitos\%20Humanos.pdf. Acesso em 13 de Maio de 2012; Art. 10. ${ }^{\circ} / \mathrm{n}^{\circ}$ 1. Qualquer pessoa tem direito à liberdade de expressão. Este direito compreende a liberdade de opinião e a liberdade de receber ou de transmitir informações ou ideias sem que possa haver ingerência de quaisquer autoridades públicas e sem considerações de fronteiras. O presente artigo não impede que os Estados submetam as empresas de radiodifusão, de cinematografia ou de televisão a um regime de autorização prévia. Fonte: CEDH, de 1953. Disponível em: http:// www.oas.org/es/cidh/expresion/showarticle.asp?artID=536\&lID=4. Acesso em 13 de Maio de 2012; Art. $11^{\circ}$ Todas as pessoas têm direito à liberdade de expressão. Este direito compreende a liberdade de opinião e a liberdade de receber e de transmitir informações ou ideias, sem que possa haver ingerência de quaisquer poderes públicos e sem consideração de fronteiras. Fonte: CDFUE, de 2000. Disponível em: http://eur-lex.europa.eu/LexUriServ/LexUriServ.do?uri=OJ:C:2010:083:0389:0403:pt:PDF. Acesso em 13 de Maio de 2012; e Art. 13. ${ }^{\circ} / \mathrm{n}^{\circ} 1$. Toda pessoa tem direito à liberdade de pensamento e de expressão. Esse direito compreende a liberdade de buscar, receber e difundir informações e ideias de toda natureza, sem consideração de fronteiras, verbalmente ou por escrito, ou em forma impressa ou artística, ou por qualquer outro processo de sua escolha. Fonte: CIDH, de 1978. Disponível em: http://www.amb.com.br/fonavid/Legislacao_Pacto_San_Jose_da_Costa_Rica_-_1969[1].pdf. Acesso em 13 de Maio de 2012.

29 Em Portugal: Art. $37 .^{\circ} / 1$. Todos têm o direito de exprimir e divulgar livremente o seu pensamento pela palavra, pela imagem ou por qualquer outro meio, bem como o direito de informar, de se informar e de ser informados, sem impedimentos nem discriminações. 2. O exercício destes direitos não pode ser impedido ou limitado por qualquer tipo ou forma de censura. Fonte: Fonte: PORTUGAL, Constituição de. Constituição da República Portuguesa. Disponível em: http://www.parlamento.pt/Legislacao/Documents/constpt2005.pdf. Acesso em 25 de Março de 2012. No Brasil: Art. 5. ${ }^{\circ}$ Todos são iguais perante a lei, sem distinção de qualquer natureza, garantindo-se aos brasileiros e aos estrangeiros residentes no País a inviolabilidade do direito à vida, à liberdade, à igualdade, à segurança e à propriedade, nos termos seguintes: IV - é livre a manifestação do pensamento, sendo vedado o anonimato; IX - é livre a expressão da atividade intelectual, artística, científica e de comunicação, independentemente de censura ou licença. Fonte: Fonte: BRASIL, Constituição do. Constituição da República Federativa do Brasil de 
"tematizada" na sua dimensão jurídico-internacional, a liberdade de expressão assume importante papel na "promoção da paz e da segurança internacionais". Noutra vertente, no plano constitucional ela é o "patrimônio indeclinável" do Estado Constitucional $^{30}$, em especial por assegurar a igual dignidade e liberdade de todos os cidadãos num ambiente de "coexistência pacífica" de todos os grupos ${ }^{31}$.

\subsection{O movimento invertido: a dessecularização}

Em sua passagem por Portugal em maio de 2010, o Papa Bento XVI afirmou, em um de seus pronunciamentos, que nesses séculos de dialética entre Iluminismo, Secularismo e Fé nunca faltaram pessoas que quisessem estabelecer um diálogo, ainda que infelizmente a tendência dominante fosse $\mathrm{o}$ da contraposição e da exclusão de um e de outro. Para o Pontífice, "a presença do secularismo é algo normal, mas a separação, a contraposição, entre secularismo e cultura da fé é anômala e deve ser superada" 32 .

Discurso à parte, o fato é que a religião tem dado

1988. Disponível em: http://www.planalto.gov.br/ccivil_03/Constituicao/Constitui\%C3\%A7ao. htm. Acesso em 25 de Março de 2012.

30 MACHADO, Jónatas E. M. Liberdade de expressão. Dimensões..., 2002, p. 61. Cfr. também: MACHARO, Jónatas E. M. A jurisprudência constitucional portuguesa diante das ameaças à liberdade religiosa. In: Boletim da Faculdade de Direito da Universidade de Coimbra, $\mathrm{n}^{\circ} 86,2006$, p. 65-134, p. 132-133.

31 MACHADO, Jónatas E. M. A liberdade de expressão. Entre o naturalismo..., 2008, p. 90 .

32 Discursos do Papa Bento XVI em Portugal, 11 a 14 de Maio de 2010. Fonte: APCM, Associação Portuguesa de Consumidores dos Media. Disponível em: http://www.acmedia.pt/ correio/papa\%20portugal.pdf. Acesso em 19 de Março de 2012. 
sinais de "grande vitalidade", como afirma Jónatas Machado, segundo o qual "depois da queda das metanarrativas ideológicas tradicionais e da relativização da soberania política, o discurso religioso apresenta-se de novo para preencher o resultante vazio, um pouco à semelhança do que aconteceu na Europa ocidental depois da queda do Império Romano do Ocidente, em $47 \mathrm{~d}$. C"33. A este fenômeno tem-se dado o nome de dessecularização da sociedade $^{34}$, cujas implicações imediatas se fazem sentir em diversos ramos da sociedade, nomeadamente no direito fundamental da liberdade de expressão na sua mais ampla acepção.

Segundo Peter Berger, na cena religiosa internacional da atualidade, os movimentos conservadores, ortodoxos ou tradicionais estão crescendo em quase toda parte do mundo, razão por que entende ser falsa a suposição de que se vive numa realidade totalmente secular. $\mathrm{Ou}$ seja, a countersecularization é um fenômeno ao menos tão importante no mundo contemporâneo quanto à secularization ${ }^{35}$, cujos efeitos já podem ser sentidos na política internacional, designadamente nas questões que envolvem os direitos humanos e a justiça social $^{36}$. Nas palavras de Jónatas Machado, a dessecularização traduz-se no "ressurgimento do fenômeno religioso" no espaço público, nacional e internacional, e anda associado à "crescente

\footnotetext{
33 MACHADO, Jónatas E. M. A liberdade de expressão. Entre o naturalismo..., 2008, p. 98.

34 BERGER, Peter, The Desecularization..., 1999, p. 2.

35 BERGER, Peter. The Desecularization ..., 1999, p. 6.

36 BERGER, Peter. The Desecularization..., 1999, p. 14 ss.
} 
insatisfação perante as explicações naturalistas do Universo e da vida e à incerteza crescente as quais envolvem o ambiente natural, a economia e o futuro" ${ }^{37}$.

É nesse cenário que a liberdade de expressão deve ser compreendida, ou seja, num ambiente complexo, onde a contraposição entre religião e secularismo representaum problema atual com variadas soluções, mas que não raras vezes se mostram insuficientes à realidade multicultural contemporânea. É que desta primeira dicotomia, outras várias podem ser enumeradas, v. g. universalismo vs. relativismo; direito natural vs. direito positivo; individualismo vs. comunitarismo; homoafetividade vs. heteroafetividade; eutanásia; aborto vs. vida; etc. Como afirma Jónatas Machado ${ }^{38}$, todas essas dicotomias têm conduzido o indivíduo a um verdadeiro "confronto mundividencial", segundo o qual "os direitos fundamentais estão hoje, em larga medida, transformados em campos de batalha ideológicos", encontrando-se a liberdade de expressão no "epicentro de um intenso confronto entre o naturalismo e a religião" 39 .

\subsection{A complexidade contemporânea e a metáfora do "Mercado Livre das Ideais"}

Como se verifica das linhas passadas, a história da

37 MACHADO, Jónatas E. M. A liberdade de expressão. Entre o naturalismo..., 2008, p. 98 e ss.

38 MACHADO, Jónatas E. M. A liberdade de expressão. Entre o naturalismo..., 2008, p. 102.

39 MACHADO, Jónatas E. M. A liberdade de expressão. Entre o naturalismo..., 2008, p. 100 e ss. 
liberdade de expressão está intimamente ligada à liberdade religiosa e à ordem secular que movimentou as principais transformações sociais dos últimos séculos ${ }^{40}$. Ocorre, porém, conforme demonstrado, que o mundo de hoje se mostra um tanto descrente da visão secular, ainda que tal fenômeno tenha suas exceções, como adverte Peter Berger ${ }^{41}$. Assim, a partir do confronto estabelecido entre a ordem secular e a religiosa, variadas visões ideológicas se digladiam numa verdadeira batalha pela sobreposição de suas "verdades", "certezas", "dogmas", "crenças" etc. É nesse contexto que se tornam "especialmente delicados os problemas relativos à definição, delimitação, ponderação e restrição do direito à liberdade de expressão"42.

Mas o confronto ideológico, político e religioso não é algo novo ou mesmo privilégio da pós-modernidade. É fato que sempre existiram os momentos de maior ou de menor tensão, v. g. a Reforma Protestante, o Iluminismo, a Independência dos Estados Unidos, a Revolução Francesa etc. John Milton, por exemplo, já no século XVII, notabilizou-se por combater duramente a censura do parlamento inglês aos livros políticos e religiosos ${ }^{43}$. Para ele, o conhecimento e a verdade só seriam alcançáveis a partir do confronto livre e aberto das ideais. Afirmava também que se nem todos podem ser da mesma

40 SILVA, Suzana Tavares da. Do fanatismo à tolerância? Necessidade de um princípio básico de pluralismo religioso. In: CANOTILHO, José Joaquim Gomes. Direitos Humanos, Estrangeiros, Comunidades Migrantes e Minorias. Oeiras: Celta Editora, 2000, p. 69-79.

41 BERGER, Peter. The Desecularization..., 2009, p. 16 e ss.

42 MACHADO, Jónatas E. M. A liberdade de expressão. Entre o naturalismo..., 2008, p. 23.

43 MACHADO, Jónatas E. M. A liberdade de expressão. Entre o naturalismo..., 2008, p. 129 
opinião, então seria mais prudente que muitos fossem "tolerados" do que todos "compelidos" 44 . Ou seja, já nos primórdios da era moderna John Milton advogou não só o direito à liberdade de manifestação do pensamento, mas também a importância de que no confronto de ideais houvesse "tolerância" para com a opinião oposta.

Ainda sobre o tratamento dispensado ao confronto ideológico, relevantes são os ensinamentos propugnados por John Stuart Mill, no ensaio On Liberty, segundo o qual nenhuma opinião deveria ser silenciada pena de estar-se a silenciar uma verdade. Para este célebre economista inglês ${ }^{45}$, a liberdade de expressão e de pensamento não representava apenas um argumento democrático, mas também um “indispensável instrumento para o homem médio atingir a grandeza mental de que é capaz"46. Ou seja, a liberdade de expressão apoia-se no "poder da razão e da comunicação livre e aberta", além de servir como "antídoto", quer ao "dogmatismo centralista, quer ao confronto violento" ${ }^{47}$.

Outro grande contributo, para melhor compreender a gravitação da liberdade de expressão, nesse contexto de intenso confronto ideológico acima exposto, diz respeito à metáfora do

\footnotetext{
44 MILTON, John Milton. Aeropagítica..., 2009, p. 100 ss.

45 MARTÍNEZ, Soares. Textos de filosofia do direito. Vol. I. Coimbra: Almedina, 2006, p. 222.

46 MILL, John Stuart. Da liberdade de pensamento e de expressão. Publicações Dom Quixote: Lisboa, 1859, p. 48.

47 MACHADO, Jónatas E. M. Liberdade de expressão. Entre o naturalismo..., 2008, p. 130.
} 
"mercado livre das ideais", proposta pelo juiz norte-americano Oliver Wendell Holmes ${ }^{48}$, segundo o qual a laissez faire do mercado de ideias, a exemplo do que sucede com o liberalismo econômico, faz triunfar aquela mais atrativa ao público. Para Holmes, a concorrência de ideias combate o monopólio do poder comunicativo e facilita o acesso de novas ideias ao mercado ${ }^{49}$.

Todavia, Jónatas Machado adverte que no limite desse mercado livre das ideias encontra-se a necessidade de "salvaguardar a abertura e a integridade dos canais de comunicação, evitando que o abuso da liberdade de uns leve ao silenciamento forçado de outros" ${ }^{50}$. Para este autor, a opção pelo mercado das ideias é uma "questão de princípio", e não um "imperativo instrumental ou uma estratégia regulatória" da liberdade de expressão nos variados canais de comunicação social ${ }^{51}$.

Destarte, pode-se concluir até o momento é que a liberdade de expressão representa um dos pilares dos regimes democráticos, assim como do Estado constitucional. Contudo, não obstante a prevalência da ordem secular, notabilizada pela figura do Estado laico, o que se vê nos últimos tempos é uma crescente revitalização do discurso religioso à escala global.

A partir dessas duas concepções de mundo, inúmeras outras dicotomias vão se proliferando mundo afora. E é nesse

\footnotetext{
48 MARTÍNEZ, Soares. Textos..., 2006, p. 237.

49 MACHADO, Jónatas E. M. A liberdade de expressão. Entre o naturalismo..., 2008, 
quadrante que se problematiza o papel do "Estado de direito democrático-constitucional" 52 , ante as disputas ideológicas que moldam a história da humanidade, ora garantindo a convivência pacífica das variadas visões de mundo $^{53}$, ora rejeitando comportamentos inadequados à realidade plural em que se vive, sem que, para tanto, ponha-se em causa o "núcleo essencial da liberdade de expressão" 5455.

Para abordar esse problema de forma objetiva é que se optou por congregar neste trabalho não só a liberdade de expressão como também o direito de reunião, designadamente quanto às reuniões ao ar livre ou nos espaços públicos, ocasião em que serão sopesadas algumas questões mais relacionadas ao tema, para que, ao final, possa-se arriscar nalgumas conclusões e reflexões.

\section{O DIREITO DE REUNIÃO}

\subsection{O direito de reunião: "a válvula de segurança da sociedade democrática"}

O direito de reunião para além de representar um instrumento de exercício das liberdades civis e políticas,

\footnotetext{
52 CANOTILHO, José Joaquim Gomes. Direito Constitucional..., 2003, p. 98.

53 MACHADO, Jónatas E. M. A liberdades de expressão: entre o naturalismo..., 2008, p. 103 .

54 QUEIROZ, Cristina M. M. Direitos Fundamentais. 2 ${ }^{\mathrm{a}}$ Edição. Coimbra: Coimbra Editora, 2010, p. 181.

55 MACHADO, Jónatas E. M. Liberdade de expressão, interesse...,2009, p. 74. Cfr. Também: TORRE, Ignacio Berdugo Gómez de La. Los límites entre la libertad de expressión y los derechos de la personalidad..., 1991, p. 19.
} 
em especial da liberdade de expressão, pode também ser traduzido numa exata condición de ejercicio doutras liberdades fundamentais ${ }^{56}$. Para António Francisco de Sousa, "a liberdade de reunião é uma liberdade pública imprescindível a toda sociedade democrática", traduzindo-se mesmo em verdadeira "válvula de segurança da sociedade democrática". Para o citado autor, "sem a liberdade de reunião não se realizam os valores do pluralismo e da liberdade da sociedade democrática", especialmente porque, por meio das reuniões, "as minorias, que normalmente estão afastadas dos centros das decisões, podem erguer a sua voz e dar a conhecer as suas exigências" ${ }^{57}{ }^{58}$.

No âmbito supranacional, o direito de reunião encontra-se consagrado nos diversos instrumentos, e.g., art. 20 da DUDH ${ }^{59}$, no art. 21 do $\mathrm{PIDCP}^{60}$, no art. $11, \mathrm{n}^{\mathrm{o}} 1$ da $\mathrm{CEDH}^{61}$, no art. $12^{\circ}$,

56 GONZÁLEZ, José Luis Lópes. Consideraciones de Derecho comparado en torno a la libertad de reunión y manifestación. Cuardernos Constitucionales de la Cátedra Fadrique Furió Ceriol no 11/12, Valência, 1995: 213-240, p. 215.

57 SOUSA, Antônio Francisco de. Direito de reunião e de manifestação no estado de direito. In: Reuniões e Manifestações: Atuação Policial, por VALENTE, Manuel Monteiro Guedes (org). Coimbra: Almedina, 2009, p. 105-115, p. 108.

$58 \quad$ SEN, Amartya. A ideia de justiça. Coimbra: Almedina, 2009, p. 17.

59 Art. $200^{\circ} / 1$. Toda a pessoa tem direito à liberdade de reunião e de associação pacíficas. DUDH, de 1948. Disponível em: http://www.oas.org/dil/port/1948\%20 Declara\%C3\%A7\%C3\%A3o\%20Universal\%20dos\%20Direitos\%20Humanos.pdf. Acesso em 13 de Maio de 2012.

60 Art. $21 .^{\circ} \mathrm{O}$ direito de reunião pacífica é reconhecido. O exercício deste direito só pode ser objeto de restrições impostas em conformidade com a lei e que são necessárias numa sociedade democrática, no interesse da segurança nacional, da segurança pública, da ordem pública ou para proteger a saúde e a moral públicas ou os direitos e as liberdades de outrem. PIDCP, Pacto Internacional de Direitos Civis e Políticos. Disponível em: http://www.operacoesespeciais. com.br/userfiles/PIDCP.pdf. Acesso em 13 de Maio de 2012.

61 Art. 11. \% 1. Qualquer pessoa tem direito à liberdade de reunião pacífica e à liberdade de associação, incluindo o direito de, com outrem, fundar e filiar-se em sindicatos para a defesa dos seus interesses. Fonte: CEDH, Convenção Europeia dos Direitos do Homem, 1950. Disponível em: http://www.oas.org/es/cidh/expresion/showarticle.asp?artID=536\&lID=4. Acesso em 13 de Maio de 2012. 
$\mathrm{n}^{\mathrm{o}} 1$ da $\mathrm{CDFUE}^{62}$, no art. 15 da $\mathrm{CIDH}^{63}$, traduzindo-se, portanto, num virtuoso direito (valor!) universal ${ }^{64}$, o que, todavia, não lhe atribui natureza de direito absoluto, tal como sucede com o direito de liberdade de expressão.

Em Portugal e no Brasil, o direito de reunião encontra-se resguargado nas respectivas Constituições ${ }^{65}$, porém com algumas distinções dignas de abordagem. Na ordem constitucional portuguesa, o direito de reunião está previsto no ${ }^{\circ} .^{\circ} 1$ do art. 45 , enquanto que o direito de manifestação aparece previsto no $\mathrm{n}^{\circ}$ 2 do mesmo art. 45 da Constituição portuguesa, o que dalguma

$62 \quad$ Art. $12 .^{\circ} /$ n. $^{\circ} 1$. Todas as pessoas têm direito à liberdade de reunião pacífica e à liberdade de associação a todos os níveis, nomeadamente nos domínios político, sindical e cívico, o que implica o direito de, com outrem, fundarem sindicatos e de neles se filiarem para a defesa dos seus interesses. Fonte: CDFUE, Carta de Direitos Fundamentais da União Europeia. Disponível em: http://eur-lex.europa.eu/LexUriServ/LexUriServ.do?uri=OJ:C:2010:083:0389:0403:pt:PDF. Acesso em 13 de Maio de 2012.

63 Art. $15 .^{\circ}$ É reconhecido o direito de reunião pacífica e sem armas. O exercício de tal direito só pode estar sujeito às restrições previstas pela lei e que sejam necessárias, em uma sociedade democrática, no interesse da segurança nacional, da segurança ou da ordem públicas, ou para proteger a saúde ou a moral públicas ou os direitos e liberdades das demais pessoas. CIDH, Convenção Interamericana de Direitos Humanos. Disponível em: http://www.amb.com. br/fonavid/Legislacao_Pacto_San_Jose_da_Costa_Rica_-_1969[1].pdf. Acesso em 13 de Maio de 2012 .

64 RAWLS, John. A Lei dos Povos. Coimbra: Quarteto, 2000, p. 88-89.

65 Em Portugal: Art. $45 .^{\circ} / 1$. Os cidadãos têm o direito de se reunir, pacificamente e sem armas, mesmo em lugares abertos ao público, sem necessidade de qualquer autorização. 2 . A todos os cidadãos é reconhecido o direito de manifestação. Fonte: PORTUGAL, Constituição de. Constituição da República de Portugal. Disponível em: http://www.parlamento.pt/Legislacao/Documents/constpt2005.pdf. Acesso em 25 de março de 2012. No Brasil: Art. 5. Todos são iguais perante a lei, sem distinção de qualquer natureza, garantindo-se aos brasileiros e aos estrangeiros residentes no País a inviolabilidade do direito à vida, à liberdade, à igualdade, à segurança e à propriedade, nos termos seguintes: XVI - todos podem reunir-se pacificamente, sem armas, em locais abertos ao público, independentemente de autorização, desde que não frustrem outra reunião anteriormente convocada para o mesmo local, sendo apenas exigido prévio aviso à autoridade competente; e Art. $220 .^{\circ}$ A manifestação do pensamento, a criação, a expressão e a informação, sob qualquer forma, processo ou veículo não sofrerão qualquer restrição, observado o disposto nesta Constituição. BRASIL, Constituição do. Constituição da República Federativa do Brasil de 1988. Disponível em: http://www.planalto.gov.br/ccivil_03/Constituicao/ Constitui\%C3\%A7ao.htm. Acesso em 25 de Março de 2012. 
forma causa interrogativas quanto à autonomia ou não do direito de manifestação ante ao direito de reunião.

Com efeito, conforme leciona Sérvulo Correia, "as Constituições mais próximas da nossa não se referem à manifestação pelo seu nome e como objecto de um direito fundamental formalmente autónomo do direito de reunião, limitando-se a destacar, no âmbito deste último, o exercício à céu aberto (Lei Fundamental alemã, art. 8, n. ${ }^{\circ} 2$ ), ou em lugar público (Constituição da República Italiana, art. 17, inciso 3)" ${ }^{\text {"66 }}$. Contudo, por mais que se possa aderir à ideia de autonomização de um direito de manifestação ante ao de reunião ${ }^{67}$, o fato é que ambos encontram-se interligados numa mesma perspectiva, qual seja, proporcionar o exercício das liberdades fundamentais ${ }^{68}$, i.e., são espécies do mesmo gênero ${ }^{69}$, ou, como nos leciona Eduardo Correia Baptista, "são simplesmente direitos com conexões"70.

\footnotetext{
66 CORREIA, Sérvulo. O Direito de Manifestação. Coimbra: Almedina, 2006, p. 16.

67 CORREIA, Sérvulo. O Direito..., 2006, p. 17 e 59, respectivamente.

68 CORREIA, Sérvulo. O direito..., 2006, p. 48-53.

69 Nesse sentido, podem-se citar as conclusões do Parecer no 30, de 2008, da Procuradoria Geral da República: "Os direitos de reunião e de manifestação, apesar das suas diferenças - desde logo, o direito de reunião é necessariamente um direito de acção colectiva e pode ser de exercício privado ou público e o direito de manifestação não é necessariamente um direito colectivo, mas o seu exercício é público e implica a expressão de uma mensagem -, são, no fundo, espécies do mesmo género". PORTUGAL, Procuradoria Geral da República de. Parecer $n^{o}$ 30/2008, Publicado no Diário da República, $2^{a}$ Série, $n^{\circ} 144$, de 28 de Julho de 2011. Disponível em: http://dre.pt/pdf2sdip/2011/07/144000000/3131331321.pdf. Acesso em 15 de maio de 2012. 70 Mas é preciso deixar claro que Eduardo Correia Baptista faz distinção entre o direito de manifestação e o direito de reunião, em que pese afirmar serem direitos conexos. Segundo o mencionado autor, "a simples circunstância de serem consagrados no mesmo artigo não constitui argumento para limitar o direito de manifestação a uma forma de gozo do direito de reunião. De outro modo, não se justificaria a sua autonomização enquanto direito do número dois". Nas conclusões deste autor, "a manifestação constitui sempre um gozo da liberdade de expressão, mas que se exerce em circunstâncias particulares". Fonte: BAPTISTA, Eduardo Correia. Os direitos de reunião e de manifestação no direito português. Coimbra: Almedina, 2006, p. 15 e 75, respectivamente.
} 
Assim, por limitação temática, prosseguir-se-á abordando somente o direito de reunião em locais públicos ou abertos ao público $^{71}$, nomeadamente no que se refere às limitações e restrições ao exercício deste direito ${ }^{72}{ }^{73}$, tudo conforme adiante segue.

\subsubsection{O caráter pacífico ainda que fervoroso do embate de ideologias}

O direito de reunião reveste-se de caráter pacífico, e as constituições nacionais como o direito internacional não deixam dúvidas quanto a isso ${ }^{74}$. Como nos adverte António Francisco de Sousa, "a reunião ou manifestação não pacíficas, isto é, que se realizam com carácter violento ou tumultuoso, não desencadeiam um processo de comunicação, mas impõem ilicitamente determinados objetivos"75. Contudo, "o caráter pacífico não implica ausência de conflito ou estrito respeito à ordem jurídica", pois os que violam o caráter pacífico da reunião são "as condutas que causam dano ou que claramente são perigosas" ${ }^{76}$, como, por exemplo, agressões a pessoas ou bens

71 Sobre a distinção entre reuniões públicas em aberto ao público e lugar público, assim como sobre reuniões privadas recomenda-se: PINHO, Pedro Miguel Marques Valente de. $O$ direito de reunião e de manifestação. A lei e a sua prática. In: Reuniões e Manifestações. Atuação Policial, por Manuel Monteiros Guedes VALENTE, 163-211. Coimbra: Almedina, 2009, p. 173. 72 CANOTILHO, José Joaquim Gomes. Direito Constitucional..., 2003, p. 450.

73 BAPTISTA, Eduardo Correia. Os direitos de reunião..., 2006, p. 167 e ss.

74 Vide art. 20 da DUDH, no art. 21 do PIDCP, no art. $11, \mathrm{n}^{\circ} 1$ da CEDH, no art. $12^{\circ}, \mathrm{n}^{\circ}$ 1 da CDFUE, no art. 15 da CIDH.

75 SOUSA, Antônio Francisco de. Direito de reunião e de manifestação..., 2009, p. 105115 , p. 110 .

76 SOUSA, Antônio Francisco de. Direito de reunião e de manifestação..., 2009, p. 105115 , p. 112 e ss. 
públicos ou privados ${ }^{77}$.

Nesse diapasão, conforme Eduardo Correia Baptista, "não faz sentido proibir todas as reuniões convocadas para fim contrário à lei”, pois, segundo o mesmo autor, "o respeito da lei não constitui um bem jurídico que justifique necessariamente restrições a direitos, liberdades e garantias"78, ou seja, o direito de reunião só excepcionalmente poderá ser objeto de controle preventivo, e mesmo assim, no que tange às suas finalidades, de acordo com a leitura constitucional luso-brasileira (e de direito internacional!), deverão atender ao caráter pacífico, i. e., perspectivada num diálogo livre, aberto, racional, tolerante etc., tal como se exige numa sociedade plural, mundividencial, multicultural como a dos tempos atuais.

$\mathrm{O}$ direito de reunião serve às liberdades fundamentais como canal de difusão e disseminação de ideologias plurais, cujo caráter não pacífico ou violento deve ser repudiado pelo Estado, de forma que assim possa garantir "a possibilidade de gozo dos bens protegidos e repor a ordem, se necessário"79, seja interrompendo contramanifestações violentas ou reuniões das quais possam resultar lesão a direitos constitucionalmente protegidos $^{80}$. Daí porque, no que toca ao conteúdo normativo das Constituições Portuguesa e Brasileira, ambas são claras em prescrever que uma reunião pacífica é uma reunião sem

77 SOUSA, Antônio Francisco de. Direito de reunião e de manifestação..., 2009, p. 105115 , p. 114.

78 BAPTISTA, Eduardo Correia. O direito de reunião..., 2006, p. 195 e ss.

79 BAPTISTA, Eduardo Correia. O direito de reunião..., 2006, p. 205.

80 BAPTISTA, Eduardo Correia. O direito de reunião..., 2006, p. 166. 
armas, cujo conceito deve ser entendido em sentido amplo, compreendendo tanto armas no aspecto técnico ou não técnico, i. e., qualquer objeto que seja adequado para lesionar pessoas ou bens ${ }^{81}$.

\subsubsection{A comunicação prévia: proteção ou restrição?}

No que se refere à exigência de comunicação prévia, aqui novamente assisti-se a uma distinção entre as Constituições Brasileira e Portuguesa. No caso brasileiro, a previsão constitucional do art. $5^{\circ}$, inciso XVI, dispõe que "podem reunirse pacificamente, sem armas, em locais abertos ao público, independentemente de autorização, desde que não frustrem outra reunião anteriormente convocada para o mesmo local, sendo apenas exigido prévio aviso à autoridade competente". Por sua vez, o art. 45 da Constituição Portuguesa enuncia que "os cidadãos têm o direito de se reunir, pacificamente e sem armas, mesmo em lugares abertos ao público, sem necessidade de qualquer autorização". Ou seja, é totalmente perceptível a distinção de tratamento do direito de reunião entre as duas ordens constitucionais supramencionadas, nomeadamente pelos enunciados linguísticos da Constituição Portuguesa que remetem a uma interpretação menos restritiva que a brasileira ${ }^{82}$.

Para José Luis López González, a ausência de qualquer

81 SOUSA, Antônio Francisco de. Direito de reunião e de manifestação..., 2009, p. 105115, p. 110-111. Cfr. Também: CORREIA, Sérvulo. O Direito..., 2006, p. 47.

82 CORREIA, Sérvulo. O Direito..., 2006, p. 62-70. Cfr. Também: Cfr. BAPTISTA, Eduardo Correia. O direito de reunião..., 2006, p. 278. 
limitação ou exigência é uma alternativa capaz de colocar em risco outros bens juridicamente protegidos ${ }^{83}$, pois o prévio aviso não equivale a uma autorização prévia; logo, não deve dar lugar a proibições que não estejam juridicamente fundamentadas ${ }^{84}$. Para Eduardo Correia Baptista, "o aviso prévio constitui uma condição de viabilidade do direito à segurança, o que parece justificar que se considere que a Constituição o impõe aos organizadores nos limitados casos em que existam riscos sérios de se verificarem consequências negativas graves em direitos de terceiros ou dos próprios participantes" ${ }^{\prime 85}$. Nessa senda, constatase que o prévio aviso tem por finalidade apenas colocar em alerta as autoridades públicas quanto à realização de uma reunião aberta ao público, para que assim possam tomar as medidas de segurança que entendam pertinentes ${ }^{86}$, visando inclusive favorecer e compatibilizar o exercício do direito de reunião com outros bens constitucionalmente protegidos ${ }^{87}$, a propósito do que dispõe o $\mathrm{n}^{\mathrm{o}} 2$ do art. 29 da $\mathrm{DUDH}^{88}$.

\footnotetext{
83 GONZÁLEZ, José Luis Lópes. Consideraciones de Derecho..., 1995, p. 234.

84 GONZÁLEZ, José Luis Lópes. Consideraciones de Derecho..., 1995, p. 216-217.

85 BAPTISTA, Eduardo Correia. O direito de reunião..., 2006, p. 275.

86 GONZÁLEZ, José Luis Lópes. Consideraciones de Derecho..., 1995, p. 216.

87 GONZÁLEZ, José Luis Lópes. Consideraciones de Derecho..., 1995, p. 227.

88 Art. $29^{\circ} / 1$. O indivíduo tem deveres para com a comunidade, fora da qual não é possível o livre e pleno desenvolvimento da sua personalidade. No exercício deste direito e no gozo destas liberdades ninguém está sujeito senão às limitações estabelecidas pela lei com vista exclusivamente a promover o reconhecimento e o respeito dos direitos e... 2. liberdades dos outros e a fim de satisfazer as justas exigências da moral, da ordem pública e do bem-estar numa sociedade democrática. DUDH, de 1948. Disponível em: http://www.oas.org/dil/port/1948\%20 Declara\%C3\%A7\%C3\%A3o\%20Universal\%20dos\%20Direitos\%20Humanos.pdf. Acesso em 13 de Maio de 2012.
} 


\subsubsection{Um caso emblemático: "Marcha da Maconha"}

Em meados de 2011, o Supremo Tribunal Federal do Brasil levou a julgamento a Arguição de Descumprimento de Preceito Fundamental de $\mathrm{n}^{\mathrm{o}} 187^{89}$, cujo pedido consistia em atribuir interpretação conforme a Constituição ao artigo 287 do Decreto-Lei n ${ }^{\circ}$ 2.848/40 - Código Penal ${ }^{90}$, a fim de excluir do campo de incidência da norma as manifestações em favor da descriminalização de substâncias psicotrópicas, em particular a denominada "marcha da maconha".

Segundo consta do voto proferido pelo relator Ministro Celso de Mello, a mencionada ADPF apontava como preceitos fundamentais violados os incisos IV, IX e XVI do artigo $5^{\circ}$ e cabeça do artigo 220 da Carta Federal ${ }^{91}$, os quais consagram as liberdades de expressão e de reunião. Aduziu-se, também, a existência de decisões do Poder Judiciário coibindo a realização de atos públicos favoráveis à legalização das drogas, as quais se

89 BRASIL, Supremo Tribunal Federal do. ADPF n ${ }^{\circ}$ 187. Disponível em: http://www. stf.jus.br/portal/processo/verProcessoAndamento.asp?incidente=2691505. Acesso em 24 de Maio de 2012.

90 Apologia de crime ou criminoso: Art. 287 - Fazer, publicamente, apologia de fato criminoso ou de autor de crime: Pena - detenção, de três a seis meses, ou multa. Fonte: BRASIL, Código Penal do. Disponível em: http://www.planalto.gov.br/ccivil_03/decreto-lei/Del2848 compilado.htm. Acesso em 24 de Maio de 2012.

91 Art. $5^{\circ}$ (...) IV - é livre a manifestação do pensamento, sendo vedado o anonimato; IX - é livre a expressão da atividade intelectual, artística, científica e de comunicação, independentemente de censura ou licença; XVI - todos podem reunir-se pacificamente, sem armas, em locais abertos ao público, independentemente de autorização, desde que não frustrem outra reunião anteriormente convocada para o mesmo local, sendo apenas exigido prévio aviso à autoridade competente; Art. 220. A manifestação do pensamento, a criação, a expressão e a informação, sob qualquer forma, processo ou veículo não sofrerão qualquer restrição, observado o disposto nesta Constituição. BRASIL, Constituição Federal do. Disponível em: http://www.planalto.gov. br/ccivil_03/constituicao/constitui\%C3\%A7ao.htm. Acesso em 24 de Maio de 2012. 
fundamentaram na premissa de que o uso da maconha é ilegal e que, portanto, a referida marcha constituiria apologia às drogas.

Por unanimidade de votos, e alheio às críticas dos mais variados setores da sociedade, o Supremo Tribunal Federal julgou procedente a arguição de descumprimento de preceito fundamental, para dar, ao artigo 287 do Código Penal, com efeito vinculante, interpretação conforme a Constituição, "de forma a excluir qualquer exegese que possa ensejar a criminalização da defesa da legalização das drogas, ou de qualquer substância entorpecente específica, inclusive através de manifestações e eventos públicos".

Dentre os argumentos utilizados pelo Ministro-relator destacam-se para citação os seguintes fragmentos:

No sistema de liberdades públicas constitucional, a liberdade de expressão possui espaço singular. Tem como único paralelo em escala de importância o princípio da dignidade da pessoa humana. Na linguagem da Suprema Corte dos Estados Unidos, se "existe uma estrela fixa em nossa constelação constitucional, é que nenhuma autoridade, do patamar que seja, pode determinar o que é ortodoxo em política, religião ou em outras matérias opináveis, nem pode forçar os cidadãos a confessar, de palavra ou de fato, a sua fé nelas" (West Virginia Board of Education v. Barnette, 319 US 624, 1943). O Tribunal norte-americano assentou, no precedente referido, não haver circunstância que permita excepcionar o direito à liberdade de expressão. Isso porque, acrescento, tal direito é alicerce, a um só tempo, do sistema de direitos fundamentais e do princípio democrático - genuíno pilar do Estado Democrático de Direito. (...)

O princípio da liberdade de expressão repudia a 
instauração de órgãos censórios pelo poder público e a adoção de políticas discriminatórias contra determinados pontos de vista. Os delitos de opinião têm um viés profundamente suspeito, se analisados sob essa perspectiva, já que impedem a emissão livre deideias. A possibilidade de questionar políticas públicas ou leis consideradas injustas é essencial à sobrevivência e ao aperfeiçoamento da democracia. Pontua Cass Sunstein que "o direitoà liberdade de expressão está especialmente preocupado em proibir o Estado de tratar pontos de vista favorável ou desfavoravelmente" (Why societies need dissent, 2003, p. 101). O artigo 287 do Código Penal atua exatamente no espaço constitucionalmente protegido, mas não é preciso declarar a não recepção do preceito pela Carta Federal de 1988. Há uma baliza segura para a aplicação da norma ${ }^{92}$.

\title{
Ao final, concluiu-se do julgamento o seguinte:
}

\begin{abstract}
Além disso, verificou-se que a marcha impugnada mostraria a interconexão entre as liberdades constitucionais de reunião - direito-meio - e de manifestação do pensamento - direito-fim - e o direito de petição, todos eles dignos de amparo do Estado, cujas autoridades deveriam protegê-los e revelar tolerância por aqueles que, no exercício do direito à livre expressão de suas idéias e opiniões, transmitirem mensagem de abolicionismo penal quanto à vigente incriminação do uso de drogas ilícitas. Dessa forma, esclareceu-se que seria nociva e perigosa a pretensão estatal de reprimir a liberdade de expressão, fundamento da ordem democrática, haja vista que não poderia dispor de poder algum sobre a pala-
\end{abstract}

92 BRASIL, Supremo Tribunal Federal do. ADPF no 187. Disponível em: http://www. stf.jus.br/portal/processo/verProcessoAndamento.asp?incidente=2691505. Acesso em 24 de maio de 2012. 
vra, as idéias e os modos de sua manifestação. Afirmou-se que, conquanto a livre expressão do pensamento não se revista de caráter absoluto, destinar-se-ia a proteger qualquer pessoa cujas opiniões pudessem conflitar com as concepções prevalecentes, em determinado momento histórico, no meio social. Reputou-se que a mera proposta de descriminalização de determinado ilícito penal não se confundiria com ato de incitação à prática do crime, nem com o de apologia de fato criminoso. Concluiu-se que a defesa, em espaços públicos, da legalização das drogas ou de proposta abolicionista a outro tipo penal, não significaria ilícito penal, mas, ao contrário, representaria o exercício legítimo do direito à livre manifestação do pensamento, propiciada pelo exercício do direito de reunião. O Min. Luiz Fux ressalvou que deveriam ser considerados os seguintes parâmetros: 1) que se trate de reunião pacífica, sem armas, previamente noticiada às autoridades públicas quanto à data, ao horário, ao local e ao objetivo, e sem incitação à violência; 2) que não exista incitação, incentivo ou estímulo ao consumo de entorpecentes na sua realização; 3) que não ocorra o consumo de entorpecentes na ocasião da manifestação ou evento público e 4) que não haja a participação ativa de crianças e adolescentes na sua realização ${ }^{93}$.

Claro está, portanto, que a atuação do Estado não se baseia apenas no respeito às liberdades fundamentais, mas também na garantia de efetivação dos direitos e liberdades fundamentais. Noutras palavras, o Estado não deve ser neutro nem estar absolutamente separado dos embates ideológicos, razão por que

93 BRASIL, Supremo Tribunal Federal do. Informativo n ${ }^{\circ}$ 631. Disponível em: http:// www.stf.jus.br//arquivo/informativo/documento/informativo631.htm. Acesso em 24 de maio de 2012. 
deve sempre atuar, mesmo na discricionariedade, com manifesto propósito de salvaguardar a abertura e a integridade dos canais de comunicação que prestigiem a discussão pública, democrática e evolutiva, ainda que muitas vezes sob os holofotes da crítica de variados domínios da vida social.

\section{CONCLUSÃO}

Superados os capítulos antecedentes, finalmente se chegou à conclusão do trabalho, local dos mais apropriados para serem reunidos os resultados obtidos ao longo dessa investigação. Relembre-se, contudo, que não houve pretensão de se esgotarem todas as questões circunscritas ao tema da liberdade expressa e do direito de reunião ${ }^{94}$. Dessa forma, sem descartar as várias conclusões apresentadas ao longo do trabalho, abaixo seguem aquelas entendidas como de maior relevância:

a) A liberdade de expressão representa um dos pilares dos regimes democráticos, assim como do Estado Constitucional;

b) $\mathrm{O}$ direito à liberdade de expressão não é absoluto e como tal deve se compatibilizar com os demais direitos, liberdades e garantias fundamentais contemplados pela ordem constitucional e internacional;

\footnotetext{
94 A propósito dessa nossa colocação: “(...) Mas nem sempre se deve esgotar tanto um assunto, que nada se deixe para o leitor fazer. Não se trata de fazer ler, e sim de fazer pensar". Fonte: MONTESQUIEU, Charles-Louis de Secondatt. O Espírito das Leis. São Paulo: Martins Fontes, 1996, p. 196.
} 
c) Não obstante a prevalência da ordem secular, notabilizada pela figura do Estado laico, o que se vê nos últimos tempos é uma crescente revitalização do discurso religioso à escala global;

c.1) A partir dessas duas concepções de mundo, inúmeras outras dicotomias vão se proliferando mundo afora;

c.2) E é nesse quadrante que se problematiza o papel do Estado ante as disputas ideológicas que moldam a história da humanidade, ora garantindo a convivência pacífica das variadas visões de mundo, ora rejeitando comportamentos inadequados à realidade plural na qual se vive;

c.3) Cuja atuação deverá sempre ter em mente não colocar em xeque o núcleo essencial da liberdade de expressão;

d) O direito de reunião, para além de representar um instrumento de exercício das liberdades civis e políticas, em especial da liberdade de expressão, pode também ser traduzido numa exata condição de exercício doutros direitos, liberdades e garantias fundamentais;

e) O direito de reunião não é absoluto e como tal deve se compatibilizar com os demais direitos, liberdades e garantias fundamentais contemplados pela ordem constitucional e internacional;

e.1) O direito de reunião e de manifestação são direitos 
conexos, ou seja, são espécies do mesmo gênero, não sendo crível, portanto, falar-se em autonomização do direito de manifestação;

f) $\mathrm{O}$ direito de reunião se reveste de caráter pacífico, contudo, isso não implica ausência de conflito ou estrito respeito à ordem jurídica, pois o que viola o caráter pacífico da reunião são as condutas que causam dano ou que são claramente perigosas, como, por exemplo, agressões físicas às pessoas ou bens públicos ou privados;

g) A comunicação ou aviso prévio não equivale a uma autorização prévia para realização do ato público de reunir para protestar ou manifestar uma ideologia comum;

g.1) A comunicação ou aviso prévio tem por finalidade precípua a de informar às autoridades públicas quanto à realização do ato público, para que assim possam tomar as medidas de segurança pública tendentes ao bom desenvolvimento do ato;

g.2) A comunicação ou aviso prévio favorece e compatibiliza o exercício do direito de reunião com outros bens juridicamente protegidos;

h) O papel do Estado não se baseia apenas no respeito às liberdades fundamentais, mas também na garantia de efetivação dos direitos e liberdades fundamentais.

h.1) O Estado não deve ser neutro nem estar absolutamente separado dos embates ideológicos, 
razão por que deve sempre atuar, mesmo na discricionariedade, com manifesto propósito de salvaguardar a abertura e a integridade dos canais de comunicação que prestigiem a discussão pública, democrática e evolutiva, ainda que muitas vezes sob os holofotes da crítica nos variados domínios da vida social.

\section{REFERÊNCIAS}

ADRAGÃO, Paulo Pulido. "Crucifixos e minaretes: a religião no espaço público. A garantia da liberdade religiosa e a prevenção de conflitos religiosos." Revista da Faculdade de Direito da Universidade do Porto. Edição especial, p. 463-473, 2010.

AMÉRICA, Constituição dos Estados Unidos da. Disponível em: <http://www.direitobrasil.adv.br/arquivospdf/constituicoes/ CUSAT.pdf $>$. Acesso em: 18 de março de 2012.

AMERICANOS, OrganizaçãodosEstados. "DeclaraçãoUniversal dos Direitos Humanos, 1948”. Disponível em: <http://www. oas.org/dil/port/1948\%20Declara\%C3\%A7\%C3\%A3o\%20 Universal\%20dos\%20Direitos\%20Humanos.pdf>. Acesso em: 25 de abril de 2012.

APCM. "Discursos do Papa Bento XVI em Portugal, 11 a 14 
de Maio de 2010." Associação Portuguesa de Consumidores dos Media. Disponível em: <http://www.acmedia.pt/correio/ papa\%20portugal.pdf>. Acesso em: 19 de Março de 2012.

BAPTISTA, Eduardo Correia. Os direitos de reunião e de manifestação no direito português. Coimbra: Almedina, 2006.

BARRETO, Irineu Cabral. A Convenção Europeia dos Direitos do Homem. Anotada. Coimbra: Coimbra, 2005.

BERGER, Peter. The Desecularization of the Word: Resurgent Religion and Word Politics (ed. Peter Berger). Grand Rapids: Michigan, 1999. Disponível em: <http://storage. cloversites.com/pathwaysformutualrespect/documents/BergerDesecularization_World.pdf $>$. Acesso em: 20 de março de 2012.

BRASIL, Código Penal do. Disponível em: <http://www. planalto.gov.br/ccivil_03/decreto-lei/Del2848compilado.htm>. Acesso em: 24 de maio de 2012.

BRASIL, Constituição Federal do. Disponível em: <http://www. planalto.gov.br/ccivil_03/Constituicao/Constitui\%C3\%A7ao. htm>. Acesso em: 25 de março de 2012.

CAILLÉ, Alain. LAZZARI, Christian e SENELLART, Michel. História crítica da filosofia moral e política. Lisboa: Verbo, 2001. 
CANOTILHO, José Joaquim Gomes. Direito Constitucional. $7^{\mathrm{a}}$ edição. Coimbra: Almedina, 2003.

CASTILHO, Antonio López. "Acerca de la liberad religiosa en el tiempo." Revista de Estudios Políticos, nº 102, 1998: 217 230 .

CEDH. "Convenção Europeia de Direitos do Homem, 1950." Disponível em: <http://www.oas.org/es/cidh/expresion/ showarticle.asp? artID $=536 \& 1 \mathrm{ID}=4>$. Acesso em: 13 de maio de 2012.

DUDHC. "Declaração Universal dos Direitos do Homem e do Cidadão.” Disponível em: <http://pfdc.pgr.mpf.gov.br/atuacaoe-conteudos-de-apoio/legislacao/direitos-humanos/declar_dir_ homem_cidadao.pdf $>$. Acesso em 18 de março de 2012.

GONZÁLEZ, José Luis Lópes. “Consideraciones de Derecho comparado en torno a la libertad de reunión y manifestación." Cuardernos Constitucionales de la Cátedra Fadrique Furió Ceriol $n^{\text {o }}$ 11/12, Valência, p. 213-240, 1995.

GUERREIRO, Sara. As fronteiras da tolerância. Coimbra: Almedina, 2005.

JAPIASSÚ, Hilton. O racionalismo cartesiano. In: Curso de Filosofia. Org. REZENDE, Antônio, 13 ${ }^{\mathrm{a}}$ ed. Rio de Janeiro: 
Jorge Zahar Editor, 2005.

JUSTO, A. Santos. Nótulas de histórica do pensamento jurídico. Coimbra: Coimbra, 2005.

KAMBOUCHNER, Denis. "Descartes (1596-1650): Felicidade e Utilidade." In: História crítica da filosofia moral e política, por Christian LAZZERI, Alain CAILLÉ e Michel SENELLART, p. 319-323. Lisboa: Verbo, 2001.

LOCKE, John. "Carta acerca da tolerância." (1632-1704). Disponível em: <http://www.dhnet.org.br/direitos/anthist/ marcos/edh_locke_carta_tolerancia.pdf $>$. Acesso em: $20 \mathrm{de}$ março de 2012.

MACHADO, Jónatas E. M. A liberdade de expressão. Entre o naturalismo e a religião. Boletim da Faculdade de Direito da Universidade de Coimbra (BFD), Coimbra, nº 84, p. 89-187, Outubro 2008.

. Liberdade de expressão, interesse público e figuras públicas e equiparadas. Boletim da Faculdade de Direito da Universidade de Coimbra (BFD), n. 85, Coimbra, 2009: 73-109.

. A jurisprudência constitucional portuguesa diante das ameaças à liberdade religiosa. Boletim da Faculdade de 
Direito da Universidade de Coimbra, no 82, p. 65-134, 2006.

Liberdade religiosa numa comunidade constitucional inclusivista. Dos direitos da verdade aos direitos dos cidadãos. Coimbra: Coimbra, 1996.

. Liberdade de Expressão: dimensões constitucionais da esfera pública no sistema social. Stvdia Ivridica, n. 65. Coimbra: Coimbra, 2002.

MARTÍNEZ, Soares. Textos de filosofia do direito. Vol. I. Coimbra: Almedina, 2006.

MILL, John Stuart. Da liberdade de pensamento e de expressão. Lisboa: Publicações Dom Quixote, 1859.

MILTON, John. Aeropagítica. Discurso sobre a liberdade de expressão. Coimbra: Almedina, 2009.

MONTESQUIEU, Charles-Louis de Secondatt. O Espírito das Leis. São Paulo: Martins Fontes, 1996.

NOTARIO, Luiz Arranz. El liberalismo conservador en la Europa Continental, 1830-1930. Los casos de Francia, Alemanha e Italia. Revista de Estudios Políticos, nº 102, p. 59-75, 1998. NOVAIS, Jorge Reis. Os princípios constitucionais estruturantes da república portuguesa. Coimbra: Coimbra 
Editora, 2004.

PINHO, Pedro Miguel Marques Valente de. "O direito de reunião e de manifestação. A lei e a sua prática." In: Reuniões e Manifestações. Atuação Policial, por Manuel Monteiros Guedes VALENTE. Coimbra: Almedina, 2009.

PORTUGAL, Legislação de. Dec.-Lei 406/74. Disponível em: $<$ http://www.gov-civil-evora.gov.pt/index.php/gce/media/files/ decreto_lei_n_1_406_74_de_29_de_agosto $>$. Acesso em: 14 de maio de 2012.

PORTUGAL, Procuradoria Geral da República de. "Parecer $n^{0}$ 30/2008, Publicado no Diário da República, $2^{\text {a }}$ Série, $n^{\circ}$ 144, de 28 de Julho de 2011." Disponível em: <http://dre.pt/ pdf2sdip/2011/07/144000000/3131331321.pdf>. Acesso em: 15 de maio de 2012.

PORTUGUESA, Constituição da República. Disponível em: $\quad<$ http://www.parlamento.pt/Legislacao/Documents/ constpt2005.pdf > . Acesso em: 25 de Março de 2012.

RAWLS, John. A Lei dos Povos. Coimbra: Quarteto, 2000.

ROLIM, Marcos. Declaração de Direitos do Bom Povo de Virgínia, de 16 de junho de 1776. Disponível em: < http://www. rolim.com.br/2002/_pdfs/0611.pdf > . Acesso em: 18 de março 
de 2012.

SILVA, Suzana Tavares da. Do fanatismo à tolerância? Necessidade de um princípio básico de pluralismo religioso. In: Direitos Humanos, Estrangeiros, Comunidades Migrantes e Minorias, por José Joaquim Gomes CANOTILHO, 69-79. Oeiras: Celta, 2000.

SILVA, Suzana Tavares da. O respeito devido ao princípio da dignidade humana: os deveres da minoria. In: Direitos Humanos, Estrangeiros, Comunidades Migrantes e Minorias, por José Joaquim Gomes CANOTILHO, 243-246. Oeiras: Celta, 2000.

SILVA, Suzana Tavares da. Direitos Fundamentais na Arena Global. Coimbra: Universidade de Coimbra, 2011.

SIMÕES, Euclides Dâmaso. A liberdade de expressão na jurisprudência do Tribunal Europeu dos Direitos do Homem. Revista do Ministério Público, Jan-Mar 2008, n. 113, p. 101$115,2008$.

SOUSA, António Francisco de. "Direito de reunião e de manifestação no Estado de direito: fundamento, significado e carácter pacífico.” In: Reuniões e Manifestações: Actuação Policial, por Manuel Monteiro Guedes VALENTE. Coimbra: Almedina, 2009. 
TORRE, Ignacio Berdugo Gómez de La. La colucion del conflicto entre libertad de expression y honor en el derecho penal espanhol. Boletim da Faculdade de Direito da Universidade de Coimbra (BDF), vol. LXV, p. 263-275, 1989.

TORRE, Ignacio Berdugo Gómez de La. Los límites entre la libertad de expressión y los derechos de la personalidad. Especial referencia a su problemática jurídico-penal. Doctrina Penal. Teoría y Prática en las Ciencias Penales, n. 53/54, p. 3-27, Buenos Aires, 1991. 